\title{
The Conceptual Politics of Race: Lessons from Our Children
}

\section{LAWRENCE HIRSCHFELD}

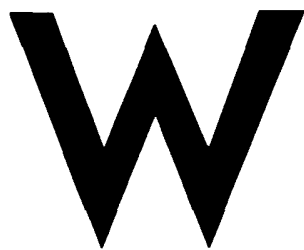

hen thinking about race there is a tendency to combine into a single package two distinct cultural practices: one racialist, the other racist. On the one hand, people effortlessly (or seemingly effortlessly) partition humans into categories based on differences in external anatomy. On the other hand, people use these categories to rationalize inequitable distributions of valued resources, power, and authority. That people engage in these practices is uncontroversial. What is contentious is the relationship between racialist and racist modes of thought, which might be called the conceptual politics of race. Psychologists, who are principally concerned with the organization of mental life, tend to view racial categories as the unmediated outcome of discontinuity in human phenotype encountering a spontaneous impulse to categorize similar things together. Of course, psychologists do not deny that representations of race play a role in the rationalization of domination and of inequity. But they tend to view this role as a by-product of the way that racial representations are mentally formed. On such a view, race is a category of power because it is a category of mind. In contrast, anthropologists, historians, sociologists, and political scientists-that is, those scholars most concerned with race as a category of power-argue that the partitioning of humans into racial categories is contingent on and derived from the particular ways power and authority are articulated in specific systems of domination. In this view, race is a category of mind because it is a category of (certain) power relations.

Both these approaches clearly have merit, and one might be tempted to adopt an eclectic reconciliation if not for one thing. Neither provides much insight into arguably the most significant aspect of racial thinking, the capacity of a system that simply represents human difference to underwrite judgments about the intrinsic value and potential of those groups represented. Thus, although thought to be directly derived from 
the visible, race invariably entails powerful claims about the invisible. It is in virtue of these explanatory claims that race serves to organize and regulate relations of power and authority. Neither traditional psychological nor comparative approaches provide purchase onto how it is that this happens since neither provides much insight into why people move so readily from the external to the internal. Indeed, both approaches situate the move outside racial discourse, despite its centrality to that discourse.

What permits racial thinking-that complex of conceptual practices and attitudes surrounding the social performance of sortings on a racial dimension-to make the move from the external to the internal, to make the move from a system for representing difference to one for explaining it? At base, it is the willingness to apply essentialist reasoning to race. Virtually all systems of racial thinking share a commitment to essentialism, a commitment to the notion that members of any particular group share a common essence that underlies the group's nature and development. Although psychologists and comparativists differ on how essentialism becomes mapped onto racial thinking, they agree that it involves the recruitment of an idea or process extrinsic to racial thinking. Thus, for psychologically minded scholars essentialism is not part of racial thinking but emerges out of processes that ensure mental economy, while for anthropologists and historians racial essentialism develops out of the articulation of racialist thinking with biological thinking.

I will suggest, to the contrary, that an adequate analysis must account for this essential, and essentializing, quality from within racial thinking itself. Indeed, I believe that such an analytic move will require a fairly modest shift in analytic strategy, one that involves reinterpreting the relationship between race as a category of mind and race as a category of power. We need simply to turn each approach on its head. On the one hand, contrary to conventional wisdom in psychology, racial thinking is intimately, not incidentally, linked to power. On the other hand, contrary to conventional wisdom in the comparative disciplines, racial thinking is readily recruited as an index of power relations precisely because it is a very specific turn of mind. In short, race is not a category of mind because it is a category of power, nor is it a category of power because it is a general category of mind. Instead, race is a category of power because it is a singular, unique category of mind.

\section{THE PSYGHOLOGICAI VERSUS COMPARATIV STUDIES OF RAEE}

In the main, psychologists' interest in race focuses on the underlying mental processes that give rise to racial cognitions and biases. To be sure, psychologists have proposed noncognitive mechanisms. For instance, it has been argued that racism is a projection of psychodynamic tensions 
intrinsic to certain personality types or that it is the outcome of certain child-rearing practices that inhibit the resolution of inherent childhood conflicts (Adorno et al. 1950). Increasingly, however, a consensus has emerged in psychology that the race concept and racial biases are byproducts of the way humans process information. In this view, the race concept follows from general features of categorization. Racial bias in its turn follows from specific features of the way human categories are organized.

The signature property of human information processing is a well-developed capacity to sort objects into categories on the basis of some perceived or imagined similarity. Such similarity-based categories are useful in part because they reduce the amount of information to which people need to attend. Many types of categories are additionally useful in that they extend our knowledge of the world. Categories, in virtue of capturing nonobvious similarities between their members, allow us to go considerably beyond the information that immediate experience provides. Natural categories (i.e., categories of naturally occurring things in the world) are particularly potent in this regard, having great capacity to underwrite a range of inferences that our immediate experience otherwise does not support. Consider, for example, the natural category COLLIE (ignoring for the moment the possibility that collies are an artifact of human intervention into canine breeding). We expect that all collies physically resemble one another. We further expect that all collies will resemble each other behaviorally (e.g., all collies tend to bark at moving cars), temperamentally (e.g., all collies show an aversion to cats), and cognitively (e.g., all collies can follow a trail of scent but no collie can learn to speak French).

In these respects, social objects are much like natural kinds. Humans readily form categories of humans on the basis of outward appearances. Humans in turn use these classifications to make predictions about the behavioral, temperamental, and cognitive properties of category members. There are, however, differences. When, in using natural categories, we move from physical correlates to other properties, we typically interpret this move to be motivated by the world's structure. The argument has the following logic: (1) Natural category members physically resemble each other (indeed, it is this physical resemblance that provides the cues for recognizing natural commonality); (2) the commonality, however, stems from something deeper, something more essential, and this inner commonality is what underwrites the fact that these categories also predict the distribution of a range of other properties (what is sometimes called the inductive potential of natural kinds). In contrast, with social categories the move from physical correlates to other properties-the move from categorization to inferences about the distribution of other 
properties (what is usually called stereotyping in the case of social categories)-is generally not explained as a consequence of the world's structure but rather is attributed to the sorts of information-processing factors that underlie categorization itself.

To illustrate this point, consider illusory correlations and in-group favoritism, two processes that have been proposed as explanations for the inductive potential of social categories. An illusory correlation is an erroneous inference about the relationship between two classes of events. Specifically, an illusory correlation is the overestimation of the frequency with which distinctive events co-occur. Take as an example the claim that race is the cause of the higher rates of crime encountered in many urban settings in the sense that blacks commit more crimes than whites. Hamilton and Gifford (1976) describe a process by which such a notion gains currency. According to their illusory correlation model,

1. Infrequent events demand more attention than frequent events;

2. The conjunction of two infrequent events is even more noteworthy than one infrequent event;

3. When two co-occurring events share a distinctive feature (such as being rare), people tend to perceive a correlation between them.

Illusory correlations underlie stereotypes to the extent that negative events are rarer than neutral or positive events, and minority individuals are rarer than majority individuals. Accordingly, people tend to attribute negative events or descriptions more frequently to minority group members than to majority group members.

In-group favoritism is another cognitive source of racial bias. $\mathrm{Al}$ though racial bias is often traceable to dynamics of power and authority, Tajfel (1981) and his colleagues have shown that in-group favoritism does not depend either on perceptions of potential group conflict or on a consolidated notion of group. Tajfel found that simply telling someone that they have been assigned to a certain group is sufficient to trigger favoritism for other members of that group. Indeed, this is the case even when subjects are aware that the basis of group assignment is arbitrary (e.g., based on the last digit of their social security number), or when they are aware that their "group" has no existence outside of the experimental context.

It is important to realize that neither illusory correlation nor in-group favoritism is specifically about race. The content of events and the specific nature of the minority status have no consequence for the model. What counts in illusory correlation is the relative frequency with which a particular type of event is encountered and the prevalence of a particular status in the social environment. Many events are rare and many social statuses are rare. It matters little whether the individual is a minority in 
virtue of his or her race or in virtue of his or her political party affiliation, sexual orientation, or preference for music. What is important is the impulse to form categories and to calibrate their occurrence with other salient (and attention-demanding) dimensions of the world. The bottom line here is that psychologists have not theorized race, they have theorized operations (e.g., stereotypy, in-group bias, and so forth) that act on racial and other categories. As a consequence it is more accurate to say that psychologists have elaborated theories about categories of objects that include (but are not restricted to) race.

In contrast to a concern with the mental correlates of race, comparativist social theorists have been interested largely in analyzing of the public representations and practices of race. On this view, race is not the inadvertent by-product of the way information is processed; it is the contrived recruitment of a post-Enlightenment impulse to systematize knowledge of natural phenomena in the service of the imperial enterprise. The European states needed to regulate and hence enumerate subjugated colonial populations, and race provided the ideological framework in which to accomplish this. As such, the idea of race is not a discovery about the structure of nature but an invention inscribed onto it.

The argument typically takes the following form:

1. Race is about relations of power;

2. Power is about aggregate structural (e.g., political, economic, or cultural) relations, not mental ones;

3. Structural relations are mental only incidentally, only to the extent that domination and subordination as lived practices minimally have to be both represented and representable, typically in some hegemonic guise;

4. Hence, a society's race concept is shaped by actually existing race relations, not vice versa.

This emphasis on systems of cultural and political domination does not mean that comparativists have failed to recognize that racial relations of power are lived by individuals in the context of everyday practice. Nor do these scholars deny that power relations have psychological correlates. Several influential works point out the crucial importance that psychological interiorization plays in imperial racism (Fanon 1968; Mannoni 1964). But these studies differ from the psychological accounts reviewed above in one crucial respect. Although it is acknowledged that historically specific systems of racial thinking may be associated with specific mental experiences, such systems are seldom explained by psychological, and particularly cognitive, causes. 


\section{RETHWKING GONVEMTOHAL WISDOMS}

It stretches credibility to imagine that an idea with the political and cultural potency of race could have purely cognitive origins. As a result, it is hardly a shock that nonpsychologists generally find cognitive accounts uncompelling. Similarly problematic for anthropologists and historians studying race is the psychological claim that race demands and focuses cognitive attention because it is impossible to ignore on perceptual grounds. Many systems of racial classification lack the supposedly clear distinctions of the racial systems that psychologists usually study. In fact, there is considerable reason to doubt that even North American racial ideology is as directly rooted in physical appearances as folk wisdom assumes (Dominguez 1986). This considerable historical and cultural variation is testimony of the fact that systems of racial classification are cultural and historical constructions, certainly not inferences based on observed human biological variation.

Problems with the comparativist position may be less apparent to many of this journal's readers. Because of this, I would like to elaborate them in somewhat greater depth. Two are particularly important and both turn on psychological issues. The first involves patterns of change in systems of domination and their supporting ideologies. The second turns on the role that race plays in causal explanation.

\section{Patterns of Political and Ideological Change}

On the comparative view, a society's ideas of race largely reflect the way that society uses race in the regulation of power and authority. Given this, we would anticipate that changes in the use made of race would result in changes in the idea itself. Rephrased, if race is a category of mind because it is a category of power (and has a particular form as an idea because of the particular role it plays in the distribution of power), we would expect racial thinking to change significantly with shifts in the underlying material basis and cultural context on which it rests. Curiously this does not always, or even frequently, happen.

Barbara Fields (1982) provides a nice example. She argues convincingly that American racial ideology is rooted in the historically specific conditions of slavery in the British North American colonies. In particular, she suggests that the idea of race (especially the idea that races are fundamentally and intrinsically different) served to reconcile a liberal political ideology of universal equality with the enslavement of blacks. Nonetheless, she found that racial ideology changed little following abolition, despite the fact that abolishment of slavery represented a fundamental, although far from complete, change in the way power and authority were distributed and enacted in North America. In the end 
Fields is not surprised by this lack of correspondence between idea (ideology) and use (slavery versus other modes of domination). She notes that political belief systems generally tend to reproduce themselves, rather than simply fading away when their supporting material conditions change: Rather than disappearing, "far the more common situation in the history of ideologies is that instead of dying, the same vocabulary attaches itself, unnoticed, to new things. It is not that ideas have a life of their own, but rather that they have a boundless facility for usurping the lives of men and women" (1982:153). I propose that this boundless facility, at least with respect to racial ideologies, emerges out of the peculiar properties of race as an idea.

\section{Race and Causal Explanations}

Another problematic issue in the comparative perspective is the causal force with which race is often attributed. Indeed, race and claims about racial difference figure prominently in a range of causal accounts. Whether offered by lay folk, scientists, or representatives of the government, answers to questions about who is impoverished, in poor health, politically disenfranchised, or poorly motivated in school invariably mention race. Unquestionably this causal potency is among the most convincing evidence that race is a category of power. However, it is important to keep in mind that the causal relationship is predominantly of the mind (or ideology), not the world itself. Race differences (differences in people contingent on their racial membership as opposed to differences attributed to people contingent on their supposed racial status) are seldom, if ever, the cause of impoverishment, ill health, lack of political power, and poor academic achievement. Other aspects of social existence (e.g., labor and class position within a social hierarchy, economic status, and cultural affiliation) are more often the basis for institutional disadvantage and more often appropriately specify the dimension along which it lies. ${ }^{1}$ Race does not explain inequities in the distribution of power and authority, it explains them away by "distorting" our perception of material relations (Winant 1994). Racial thinking serves both to legitimize and to misrepresent the way power is wielded and opportunity apportioned.

If changes in racial thinking are not directly tethered to changes in the political context, and if racial thinking distorts rather than reflects the material basis to which it is linked, then does it make sense to explain race (or the idea of it) by reference to political and material relations? Yes and no. Yes, to the extent that race and the political and material environments in which it is found are strongly associated. No, to the extent that this association is unmediated. When comparativists argue (or more often assume) that a society's ideas of race largely reflect the way race is used in the regulation of power and authority, they generally talk 
about this relationship as if it were unmediated (or uninterestingly mediated) (see Hirschfeld 1996 for a review).

Indeed, this is not all that remarkable in view of the empiricist epistemology that permeates most social science. On this view, very little is thought to mediate between an idea and the conditions of existence it represents. However, there is now growing skepticism about this claim, and it is increasingly apparent that our cognitive endowment crucially mediates between experience and representations of it (for reviews, see Hirschfeld et al. 1982; Hirschfeld and Gelman 1994). Few continue to view learning as the passive internalization of an external environment, be it material or ideological. Instead, what was traditionally seen as learning is now understood to be the outcome of the interaction of a variety of endogenous programs for acquiring knowledge with a complex environment.

In the case of race this sort of cognitive mediation seems especially likely. Recall that a number of comparativist scholars argue that racial beliefs distort the material reality that these beliefs supposedly describe. Distortion is a mental predicate. An idea distorts a reality to the extent that there is some psychological mediation between the experience of a reality and its representation. For racial categories the mediation is exceptionally obvious. According to most racialist systems of belief, humans are not only partitionable into racial groups, these groups are thought to be natural. Race distorts the material reality (of human biological variation) by drawing attention away from it and toward another, conceptually more natural, dimension. The naturalization of race is a major factor underlying the political potency of race to organize power and authority. Indeed, authority is the naturalization of power, the rendering of a particular power situation as "a fact in the nature of the world" (Bloch 1974:79). Few ideas are more effective in this regard than race. As Stuart Hall (1980:342) observes, race "discovers what other ideologies have to construct: an apparently 'natural' and universal basis in nature itself."

The question of interest is where does a naturalized notion of race come from? For many historians and anthropologists the phenomenon has social origins: the naturalization of race is part of the modern elaboration of social ideology, originally rooted in post-18th-century beliefs about cultural variation converging with a particular (and legitimizing) theory of biology (Appiah 199); Goldberg 1993; Guillaumin 1980; Takaki 1992). According to this theory, race is naturalized to the extent that it is biologized or mapped onto a modern theory of biology. The "natural" notion of race is "the belief that groups are naturally diverse, because of endogenous characteristics which are determining factors in 
themselves, independently of history or economics" (Guillaumin 1980:45).

\section{RAEE VEBSUS NOT RAGE}

Scholars in the comparative tradition do not deny that prior to the European imperial enterprise people conceived of themselves and others as belonging to specific groups whose members shared a range of common and fundamental properties. Racial ideology supposedly stands apart from these antecedent forms because of the special power relationship with which the modern idea is invested and the special kind of (biological) commonality that supposedly is shared among members of the same race. Race is a historically unique phenomenon, rising out of a singular confluence of cultural, political, scientific, and economic events and practices that defined a particular set of political relations. To the extent that this is the case, it should be possible to discern whether a system of classification is racial by assessing the degree to which it is structured around the relevant (folk) biological beliefs, specifically expectations about the embodiment, naturalness, perseverance, and invisible causal force of race. In fact, a number of scholars have employed just such a strategy as a racial acid test.

Takaki (1992), for instance, identifies the moment that racial thinking emerged in British North America during the 17th century. He argues that this occurred when colonists shifted their interpretation of Indian "savagery" from a matter of culture (defined as a redeemable state of savagery) to a matter of nature (defined as an irredeemable state of savagery). The shift he describes is subtle, in significant measure because, as Takaki makes clear, the British had long used a racial-like (but not-yet-racial) discourse to characterize the other colonized populations. Indeed, he notes that the language of political discourse about the Irish, which considerably predates that about the indigenous population of North America, was virtually indistinguishable from that used to describe the latter. Still, Takaki argues there is a fundamental difference in the two discourses. "Although [the English] saw the Irish as savages and although they sometimes described this savagery as 'natural' and 'innate,' the English believed that the Irish could be civilized, improved through . . . 'nurture.' In short, the difference between the Irish and the English was a matter of culture" (1992:895). In contrast, the difference between Native Americans and the English was natural. Native Americans, in the British view, were quite literally dehumanized, demonized, and naturalized: "Indian identity became then a matter of 'descent.' Their racial markers indicated ineradicable qualities of savagery" (1992:907). 
It is not clear, however, that the distinction between nature and nurture, redeemable and irredeemable, on which Takaki sets so much significance is really all that critical historically. We know that in current thought much weight is placed on racial-versus-cultural (or ethnic) difference, and a number of scholars have proposed that the two phenomena are distinct (Smedley 1993; Sollors 1986). Despite this, there is considerable evidence to suggest that a principled (and not historically contingent) way of drawing the distinction is difficult to identify. For example, many contemporary ethnic groups (groups whose commonality is now thought to turn on matters of culture) were until recently considered racial groups (groups whose commonality is thought of as a matter of heredity). Southern Europeans, Jews, and indeed the Irish in America were considered nonwhites during the first decades of the 20th century (Alba 1985; Roediger 1994). It may well be, as Takaki argues, that there were subtle differences in the way English colonizers mentally represented and imaged the Irish and the Indians, and it may be that this involved differences in the scope of redeemability attributed to each. But this does not imply that one group was racialized and the other not. It may imply that under current interpretation, one group would be racialized and the other not. But it does not follow that current habits of interpretation are informative of 17 th-, 18th-, or 19th-century systems of belief.

A similar argument can be made about the identification of race with a specific sort of naturalization, namely biology. Guillaumin (1980) argues that it was only after the elaboration, in the 19th century, of a biological theory for explaining the heredity of somatic traits that an essentialist vision of race became possible (1980:54; see also Appiah 1990; Smedley 1993). In this view, race is a fairly modern and historically specific notion. Undoubtedly a major and extensive elaboration of racialist theory occurred during the late 19 th and early 20 th centuries. Just as clearly, during this same period theories of biology came to occupy pride of place in public discourse on race. This certainly makes it appear that racial thinking is fundamentally linked with the rise of biological science (and biological scientism, the lay interpretation, and implementation of biological theory). However, we should take care to keep the horse before the cart. The relationship between modern biology and race is important because it is a mapping of a theory of the natural world onto a theory of human variation. In this regard, the relationship between biology and race is one between ethnotheory about natural causality and a claim about human diversity. The important point to bear in mind is that all systems of racial belief make reference to natural causality (Hirschfeld 1996). There is no reason to assume that modern biological causality is the only natural causality we encounter in racial discourse. 
Indeed, there is good reason to believe that the basic building block of naturalization, essentialist reasoning, may not be directly related to biological thought at all. As Douglas Medin (1989) has pointed out, essentialist reasoning may well be an integral part of our cognitive expectations of the world generally. Unlike philosophers who have sought to link essentialist reasoning to essences in the world (e.g., Putnam 1975), Medin proposes that people have a distinct way of thinking about essentialism that is largely independent of the way that mental essences (psychological essences) might be linked to real essences (metaphysical essences). He argues that "people act as if things (e.g., objects) have essences or underlying natures that make them the thing that they are... . It is important to note that psychological essentialism refers not to how the world is but rather to how people approach the world" (Medin 1989:1476-1467).

If psychological essentialism is, as Medin argues, "bad metaphysics" and owes little to encounters with the real (metaphysical) essences, where does psychological essentialism come from? He makes the following, and compelling, proposal: "why should people act as if things had essences? The reason is that it may prove to be good epistemology. One could say that people adopt an essentialist heuristic, namely, the hypothesis that things that look alike tend to share deeper properties (similarities). Our perceptual and conceptual systems appear to have evolved such that the essentialist heuristic is very of ten correct" (Medin 1989:1476).

Intriguingly, several scholars, notably Gordon Allport (1954), have offered much the same explanation for racial essences. According to Allport, racial essentialism is also grounded in cognitive instrumentality, specifically what he calls the principle of least effort. Racial thinking is useful because it saves processing time: "To consider every member of a group as endowed with the same traits saves us the pains of dealing with them as individuals" (1954:173). In this regard, both Medin's and Allport's views contrast with the comparativist position that situates essentialist reasoning in specific historical and cultural configurations (e.g., Fuss 1989). In their views essentialism is a property of the mind, not a property of a particular system of power or its ideological legitimization. ${ }^{2}$

I would like to go further and propose that racial essentialism is not only a property of the mind; it is a domain-specific property of the mind. The essentialization of racial kinds is not the by-product of a general impetus for cognitive economy, that is, an effect that emerges in the context of all systems of categorization. Rather, it represents a very specific turn of mind. It is precisely because race is essentialized that it serves systems of power and authority so well. Accordingly, it may make more sense to say that race is a category of power because it is a category of mind than to argue that it is a category of mind because it is a category 
of power. But this makes sense only when we qualify "category of mind" by saying "a very specific category of mind."

\section{TWO CAVEATS}

Before going further, it is important to underscore what I am not suggesting. Two points are critical: first, I am not claiming that race is a natural category of the mind; and second, I am not claiming that racial thinking is impervious to the cultural or political environment in which it is found.

Let me address each of these in turn.

\section{Race Is Not a Natural Category of the Mind}

What I suggest is that the abstract principles that give rise to racial thinking probably are natural to the mind. Humans know a tremendous amount about other humans-arguably they know more about other humans than anything else. It is not surprising, then, that humans know quite a bit about the scope and nature of the groups or collectivities into which humans coalesce. After all, a hallmark feature of humans is their proclivity for living in groups and forming coalitions. Life in the complex and multilayered social environments that humans inhabit is possible only to the extent that humans have sufficient capacities to mentally represent and identify with these groups and coalitions.

The argument that humans have a special-purpose mental faculty for reasoning about humans in groups is not all that surprising given what we now know about the faculties that humans have for reasoning about other domains of the world. A rich multidisciplinary literature supports the notion that the human mind is composed of independent modules, faculties, or domain-specific competencies (the appropriate descriptive term depends on the theorist one consults), each of which is specialized in processing a particular range of information and guides hypothesis formation and reasoning about a more or less well-bounded phenomenon. Considerable work, for instance, explores the child's theory of mind and traces it to an evolved module for thinking about behavior as motivated by states of mind (i.e., beliefs and desires). Similarly, much work provides evidence for a naive mechanics and traces it to an evolved module for thinking about the physical world in more or less Euclidean terms (for detailed discussion, see the introduction and other relevant chapters in Hirschfeld and Gelman 1994). It is thus plausible to imagine that the development of a representational system for thinking about human coalitions is facilitated by an endogenous curiosity deeply rooted in our cognitive endowment. 
Indeed, humans have a spontaneous curiosity and a rich representational system for thinking about human groupings of a particular sort-collectivities based on intrinsic commonalities between group members. Elsewhere I have argued that this curiosity and representational system flow from a module (Hirschfeld 1996), perhaps even an evolved mechanism for developing knowledge of human kinds. What would this module look like? First and foremost it would consist of a willingness to make certain ontological commitments, in particular the commitment that the human world is composed of distinct types or kinds. A range of human kinds is possible. There are kinds based on common behavioral features, kinds predicated on common physical features, kinds predicated on common emotional characteristics, and so on. Like other domain-specific devices, the human kind competence is comprehensive. People not only create human kinds (in the sense of sorting individuals into relevant kinds) but also assume that in virtue of category membership individuals who might otherwise be dissimilar are fundamentally alike in their nonobvious and basic natures. As we will see, this is a crucial point. The human kind-creating competence delivers categories that do not embody difference, they interpret it. Race is one of the most recurrent ways of thinking about intrinsic commonalities and human kinds. Whether it is a universal way of categorizing the world is not of great import. Clearly, it is a common way to partition the social world and an easy one to learn. My argument is that this is so in part because racial thinking emerges out of the operation of a more general human kind mode of reasoning about human difference. What is natural is not a racial turn of mind but a human kind one. The race concept emerges out the operation of the human kind module as it makes contact with certain environmental conditions.

Because innate modules have been linked to evolved mechanisms, it is worth taking a slight detour to ask how evolution may have shaped a human kind module and how my claims about it differ from other claims about the evolution of human sociality. At least three different evolutionary issues are related to the question of a human kind module: (1) the evolutionary advantage of group living (e.g., the cost and benefits of sociality); (2) how evolution shaped behavioral and mental responses that might facilitate group living (e.g., the development of detectors for recognizing members of one's own group or the development of patterned behaviors toward and attitudes about in-group members versus strangers); and (3) conceptual structures that might guide the formation of hypotheses about the scope and nature of human group living (e.g., the development of an ontological commitment to groups as atoms of social experience). 
With reference to the first evolutionary issue, quite a bit of speculation focuses on why humans live in groups and what mental correlates there may be to group living. Theorists from very different perspectives ground sociality (i.e., the cognitive basis for group living) in processes of reciprocity (Alexander 1979, 1987, 1989; Lévi-Strauss 1969). A number of evolutionary explanations have been offered, mostly involving the positive consequences that reciprocal social systems have for resource management and exploitation (Wrangham 1980) and the protection that group living provides against predation. The latter includes predation both from within the group (as when females bond to defend against coercion by males within the group [Brereton 1996]) and those from outside the group (as when group members live in groups to protect themselves against predation by conspecifics (Shaw and Wong 1989; Warnecke et al. 1992).

With respect to the second issue, most interest in the evolution of the mental correlates to group living centers on one of two phenomena: (1) the ways by which humans identify individuals who are members of their own group (Shaw and Wong 1989; van den Berghe 1981), or (2) the way in which identification of members of one's own and other groups (i.e., judgments of in-group versus out-group) are tied to attitudes and behaviors that promote group cohesion, typically through the development of in-group favoritism and out-group enmity (Fishbein 1996; Reynolds 1987; van den Berghe 1981). As a result, when evolutionary theorists discuss race they tend to focus on racism, particularly on how adaptations that foster in-group favoritism and out-group enmity might underlie later-developing ideologies like racism, ethnocentrism, or nationalism. ${ }^{3}$

With respect to the third issue, evolutionary studies have traditionally sought to identify mechanisms and principles that produce behaviors (like in-group favoritism and out-group enmity) that make greater or lesser contributions to genetic fitness. Less attention has been given to mechanisms and principles that produce cognitive goals that under differing conditions give rise to a range of behaviors and beliefs that contribute to genetic fitness (Dunbar 1988). The evolved mechanism I propose is more closely linked to goals than specific behaviors. To better convey what I mean by goals versus behaviors, consider the following two plausible adaptations: the first involves a flight reaction to disturbances on the ground that might be made by a snake; the second involves a preparedness to interpret behavior as resulting from an individual's beliefs and desires. The first could well be fixed in the mind as a simple behavioral sequence; the perception of certain movement in the grass causes flight. It works without conceptual mediation in the sense that it occurs without ever having to call up a mental image of a snake, associ- 
ating that image with danger and inferring "time to run." The second sort of adaptation, in contrast, requires conceptual mediation, in particular a willingness to attribute mental states like belief and desire, and a commitment to interpret behavior as being directly linked to such states. The second sort of adaptation, then, involves a goal: given certain stimulus conditions (i.e., human behavior), try to find an interpretation that includes beliefs and desires. The first sort of adaptation does not involve a goal: given certain stimulus conditions (i.e., movement in the grass), flee.

The human kind module is an adaptation of the second sort because it does not directly deliver specific beliefs about the dimensions on which groups might form or how individuals might value each other. Rather it guides how humans come to represent the world's social structure. Many nonhuman social animals appear to have specific beliefs about intergroup relations in that they appear to display in-group favoritism and out-group enmity (Fishbein 1996). Moreover, some nonhuman primates appear to display rudimentary group predicates in that they infer "general properties of social relationships and compare relationship on the basis of these properties" (Cheney and Seyfarth 1990:61). Still, both of these phenomena are in principle independent of a capacity to form goals like those that I suggest a human kind module provides, namely a willingness to represent the world in terms of corporate social entities. In short, the mere identification of an individual as belonging to a privileged group (or identifying another individual as not belonging to that group) is not the same as understanding social existence in terms of group entities.

Consider an analogous phenomenon. Neonates can reliably distinguish their mother's native language from other languages, even when the speaker is not their mother and even when they are presented with highly degraded samples of speech (Mehler et al. 1988). We could not conclude from this that neonates have a (meta)conception of language or that they have a conception of languages. Rather they appear to be equipped with detectors that permit them to distinguish some class of speech from others. But this capacity underdetermines the child's eventual ontological commitment to the idea that there are multiple languages in the world (Hirschfeld 1996). Children or other species may reason in accord with adults in many respects. But this does not mean that they share theories. The same thought can be consistent with more than one theory.

Finally, speculation that there is a direct link between recognizing social difference and predicating action on it may overestimate how useful such a link may be. For instance, thought experiments by evolutionary theorists aside, the image of intense intergroup competition during the Pleistocene in which xenophobic hostility was pandemic is not as well supported by the anthropological evidence as is often supposed. Many of 
the hunter/gatherer groups that theorists rely on to gain insight into our ancestral populations' social life are in fact refugee populations who have been pushed fairly recently into marginal environments. There is little reason to believe that our ancestral populations lived in environments as hostile as that, say, of contemporary Bushmen, and thus there is little reason to believe that the environment of our ancestral population selected for adaptations necessary to survive under such conditions. Similarly, basing our models of ancestral social experience on the Yanomomi, particularly the violence of their society, distorts what aboriginal life before contact may have been like. For instance, first-contact reports document both a freedom of movement across group boundaries and a lack of sharp frontiers between groups. Indeed, Fried (1975) convincingly argues that corporate notions like the tribe are inadequate descriptions of aboriginal groupings.

No other social creature lives in groups as fluid and complex as humans. Human societies, even the least elaborated ones, require that each actor has multiple social identities and multiple group affiliations, be they gender- or age- or kin-based. If human cognitions about groups were simply a direct and genetically determined response to encounters with markers of group difference, we would have chaos, not ethnocentrism. Humans and other primates represent and attend to relationships between individuals, not just to badges of similitude and difference (Alexander 1987; Dunbar 1988). From an evolutionary perspective this means that we need to explain how humans come to conceptualize multiple and orthogonal dimensions of social affiliation, how they come to apply the valuative calculi of racism, ethnocentrism, or nationalism, and how they come to predicate action on such evaluations. If, however, humans were prepared to develop a commitment to an ontological level of corporate group existence, these tasks would be facilitated. It is this capacity for thinking about the human world as comprised of corporate groups as well as individual actors that I seek to capture when describing a human kind module as evolved mechanism.

\section{Racial Thinking Is Underdetermined by the Human Kind Module and Is Thus Not Impervious to the Cultural and Political Environments in Which It Occurs}

The readiness to categorize humans into human kinds would necessarily underdetermine any particular system of social referencing. Social belief does not spring from a human kind module, it is enabled and guided by it. In order to produce a system of social belief, the human kind module must make contact with a cultural environment. The analytic trick is to understand how, when, and in what way cultural, political, and other 
ideological systems recruit innately guided strategies for acquiring knowledge of human kinds.

Systems of racial thinking vary considerably across cultures and historic time. My proposal neither denies this variability nor implies that it is trivial. Nor am I suggesting that racial thinking is impervious to the cultural and political environments. Indeed, racial thinking is literally unthinkable in the absence of such environments. Something, and typically it is a system of cultural belief, channels an abstract set of expectations about human difference onto a specific range of differences and a specific way to viewing them. In some, in fact in many, social formations this turns out to be racial. But the range of ways of interpreting raciality vary considerably, and therefore the way these abstract principles derive substance varies accordingly. Some systems, like the contemporary North American one, focus on visible and dramatic differences in appearance. Other systems, like the midcentury German one, draw more attention to public sociology than to accessible morphology.

\section{CHIIDRE AND RAGTaL THINKING}

Earlier I presented the following argument: If racial categories take form in virtue of the political purposes they serve and the cultural environment in which they emerge, then we would expect that features of racial thinking that are historically specific and politically contingent will be found only in the corresponding historical and political environments. It has been widely accepted in the comparativist literature that racial thinking is naturalized and essentialized in virtue of being structured around modern beliefs about the embodiment, naturalness, perseverance, and invisible causal force of biological traits. These principles of reasoning about biological phenomena have been transferred to the social realm as part of the imperial colonial enterprise's naturalization of human groups.

One way to assess whether this is the case is to appraise how closely tied this version of racial traits is to this particular confluence of political and cultural factors. Is race naturalized only in the context of 19th- (or 18th- or 17th-) century European political economy? Is race essentialized only when tied to the modern notion of biological essence? If race is naturalized in cultural formations in which essentialization plays little role in the regulation of power and authority, then we have persuasive evidence that neither naturalization nor essentialization are politically derived or politically contingent. In short, if racial thinking is essentialized even in systems of thought in which race is unpoliticized, this would suggest that its potency as an idea may derive more from its mental properties than from the place it occupies in a system of political ideology. 
$\Lambda$ major problem with actually pursuing this comparative research strategy is that it is no longer possible, indeed it may never have been possible, to find a cultural formation in which race is not politicized, even if only by leakage from more dominant systems of belief and power. Political ideologies are by definition embedded in systems of hegemony; and systems of hegemonic relations bleed at the seams. By intent or not, systems of political belief that serve to sustain systems of unequal power tend to influence belief systems that at first blush seem outside their purview. Still, the problem is not insurmountable. There is one comparative strategy that is available and informative. Our children's racial beliefs and political ideologies are not exactly ours. It is possible to examine the development of our children's racial beliefs and explore the relationship between these beliefs and the role race plays in regulation of juvenile power. On the face of it, this seems a curious empirical strategy. For one thing, it is not exactly a cultural comparison. While our children's and our thinking may not always match, they are nonetheless closely linked. In fact, a number of influential approaches to maturation cast the child as little more than an incomplete, often inept, imitator of adult practice and belief. Is it fair, then, to interpret child/adult differences as a cultural contrast?

As counterintuitive as it may seem, I believe that there is ample evidence for saying yes. A body of work is now emerging on children's and youth cultures that suggests that we must view childhood not simply as a period for acquiring and imitating adult cultural competence, but as a time of (sub)culture construction. This in no way implies that children neither acquire nor imitate adults and adult practices. It is, however, to reject two tropes that have dominated modern Western views of children: the innocent child and the developing child. Both take childhood to be a period in which the child's principal task is to evolve toward a fixed adult endpoint. Most importantly, both take childhood to be a period of sustained and marked incompetence. In this view, children speak, act, and think as they do because they are incapable of doing much else. Their speech, actions, and thoughts are pale imitations of the adult counterparts.

In view of how deeply these beliefs are entrenched in modern Euro-American culture, it is remarkable how historically recent this image of the child is and how few other cultures have embraced it (Ariès 1962). ${ }^{4}$ In many parts of the world and in many historical epochs, it would be and would have been curious to claim, as we generally do, that children are cognitively incomplete and socially inept creatures. Rather, children are seen as strikingly competent beings whose lives are embedded in, but not solely shaped, by the lives of the adults with whom they share a life space. Finally, many now acknowledge that children live in cultures 
significantly of their own making, cultures that are interestingly distinct from and often in counterpoint to the adult cultures surrounding them. Children's culture is as much a distinct construction as it is a version of adult culture. Increasingly, ethnographically oriented scholars in the modern Euro-American tradition are recognizing this (Amit-Talai and Wulff 1995; Corsaro and Eder 1990; Hirschfeld 1996).

Several lines of evidence converge to indicate that preschool culture in the United States is racially unlike that of adults, despite how deeply saturated American life is with a particular racial ideology. Part of the distinctiveness of preschool children's racial culture flows from the fact that young children's racial experience (i.e., experience with racial difference) is often quite unlike that of adults. For instance, because of the hypersegregation of American life (Massey 1993), young children, of all backgrounds, often have few opportunities for extended contact with peoples of other races. Moreover, many minority families structure young children's experience in ways that buffer the impact and consequences of the dominant racial politics (Jackson et al. 1988). Perhaps most striking, American parents studiously avoid talking about race with their young children (Kofkin et al. 1995). Finally, a number of naturalistic and experimental studies have found that race plays little role in organizing young children's behavior and occupies little space in children's speech (Aboud 1988; Hirschfeld 1988; Holmes 1995).

All this suggests that race is less salient to young children than we might otherwise imagine, given how salient it is in American society. Germane to this discussion, race also appears to lack the political significance for young American children that it has for adults. What I mean by "lack of political significance" is the observation that race plays little role in shaping children's choice of association and little role in determining how resources under children's control are distributed. As an example, young children's choice of playmates is little affected by race. It is not simply that young children are innocent of or inattentive to human group differences when choosing playmates. Age, gender, and even native language (for bilingual children) are important factors in children's willingness to befriend other children (Doyle 1983). But not race. Perhaps the strongest evidence that race lacks the same political valence for young children as it does for adults is the lack of racial difference in children's racial practices and beliefs. Unlike adults, whose beliefs about race vary considerably depending on the race of the individual involved, for children we find little effect for race of child.

In brief, children's social praxis is much as their parents would like it to be-color blind. However, this pattern of nonracialized behavior and speech is not, contrary to conventional wisdom, because young children are literally color blind. Young children recognize and attend to differ- 
ences in physical appearances, including race. They, like adults around them, have named racial categories. They can use these racial categories to make sense of social experience if not to organize social behavior (Hirschfeld 1993, 1995.)

The favored explanation for the relative absence of a juvenile racial politic is that race has a fundamentally different meaning for young children than it does for the adults around them (Aboud 1988; Holmes 1995; Katz 1982). According to this view, young children conceive of race as a superficial quality of people, one that is literally skin-deep. Adults, in contrast, invariably see race as capturing much more than difference in outward physical features. For adults, race is not simply a catalogue of human difference, it is an account of the nature of that difference. In brief, adults see the visible qualities of race as signals for more important invisible qualities. Thus, for adults, on this view, race is about physical appearance, but it is also about racial essence; for children, race is only about physical appearance, never about essence.

If this were the case, it would lend support to the claim that the naturalization of racial thinking coemerges with the politicization of race. Adults politicize race, children do not; adults essentialize race, children do not. This conclusion turns on children's racial thinking being as superficial and unessentialized as previous work suggests. The principal support for the claim that children interpret racial and other social properties superficially comes from studies purporting to show that young children overestimate (compared with adults) the importance that appearances play in determining identity. For example, when asked what happens if a person's hair and clothing are changed in gender-relevant ways (e.g., by dressing a boy in girl's clothes), children up to seven years of age typically say that the person has changed sex (Carey 1985; Emmerich et al. 1977; Gelman et al. 1986; Kohlberg 1966; Slaby and Frey 1975). Parallel studies have shown that children make similar judgments about a person whose racial or ethnic appearance undergoes a similar rapid change. For example, when preschoolers are asked if a non-Eskimo dressed up like an Eskimo is an Eskimo, they tend to answer yes (Aboud 1988; Ramsey 1987). Similarly, when Semaj (1980) asked young black children if they were still black when they put on white makeup and a blond wig, they typically responded no. These findings have been interpreted as evidence that before age nine children fail to conserve racial identity across perceptual transformations.

The question of essence arises because young children's apparent failure to understand both gender and racial constancy is interpreted as evidence that children do not understand that identity is tied to a small set of deep biological properties. The development and elaboration of these biological properties is tied commonsensically to the transfer of 
invisible but material essences from parent to offspring. Thus, in the case of race, young children's failure at racial-constancy tasks is understood to indicate that young children are unaware of the biological origins of racial features (i.e., their constancy over the life span), and that a person's racial features are a function of the racial features of his or her parents (Aboud 1988). The importance of these findings is evident if we contrast them with the supposed adult pattern of response to the same question (I say "supposed" because there has been relatively little corresponding research among adults). For adults, change in sex would only occur if essential properties were altered. Changes in accidental properties, like clothing or hair length, do not produce identity shifts. Moreover, for adults, changes in essential properties are difficult to imagine and thought to be difficult to achieve (consider the debate about sex-change operations). In contrast, changes in accidental properties are relatively easy to imagine and enact.

How convincing are the findings that children do not share this essentialist view of race or that they are incapable of distinguishing racial properties from other less "natural" properties? Gelman et al. (1994) propose the following criteria for essentialist reasoning: (1) explicit articulation of an essentialist philosophy, (2) an expectation of immutability (or constancy) of identity over superficial transformation, (3) appeal to invisible causal mechanisms, and (4) assumption of innate disposition. Adults believe that all four of criteria apply to racial essences (see Hirschfeld 1996 for a review). I have conducted a series of studies showing that all but the explicit articulation criterion (children do not talk about race, so we can hardly expect them to talk about racial essences) characterize young children's reasoning about race (Hirschfeld 1988, 1993, 1995). In the briefest terms, these studies demonstrate that by three years of age, children have a much more adult-like understanding of race, and particularly racial essentialism, than previous scholars have credited them with. ${ }^{5}$ Even quite young children expect racial identity to be linked to family background, inherited, and impervious to environmental influence. Most important, these studies show that children's reasoning about race is unlike their reasoning about other identity-relevant traits that have similarly rich physical correlates. For example, even three-year-olds believe that a child is more likely to racially resemble its parents than to resemble them in physique. (Despite the fact that a person's physique is linked to family background, is inherited, and is largely immutable over the life span.) These findings strongly indicate that even quite young children's expectations about racial constancy are more essentialized and less perceptually bound than earlier studies suggest.

As an illustration, let me describe one of the studies that provides particularly powerful support for this conclusion. Recall that according to 
earlier researchers, young children believe that racial identity is shaped by conditions of social existence, not biology. To test this more directly, we asked young children what happens when infants are switched at birth and raised by adoptive parents whose race is different from that of the birth parents. Specifically, we told a group of young children about two families, one black the other white, who had babies on the same day at the same hospital. ${ }^{6}$ Inadvertently, however, each couple took the other couple's baby home with them. We stressed the importance of pregnancy to birth (by remarking that the baby came out of the mother's tummy) and highlighted the social correlates of parenting (by telling children about the care, feeding, and affection that the adoptive parents gave the child). We told the children that these infants grew up and eventually started school. We then showed them pictures of two school-aged children, one who racially resembled the birth parents, the other who racially resembled the adoptive parents. Children were then asked to identify which was the child at school age. We figured that if children believe that race is a socially determined property, they would choose the baby that matched the race of the adoptive parents. If they believe that race is a biological or natural property impervious to social existence, they would choose the baby that matches the race of the birth parents. The results were quite clear. Most three-year-olds and virtually all four-year-olds chose the child that matched the birth parents' race, clearly demonstrating that they believe that an individual's race is set in a person's nature, not in the conditions of their nurture. Clearly, children naturalize race.

These findings, however, do not tell us whether children believe that race is more naturalized than other properties, particularly nonracial physical ones. That is, the findings do not tell us whether children are generally nativists or whether they are nativists only about some kinds of attributes. Earlier work aside, perhaps young children believe that all kinds of properties are deep (or intrinsic). Alternatively, they might believe that race and other inherited properties are deep, but still doubt that material transfer has anything to do with their reproduction. The issue is important because the question we are trying to resolve is the role that the political environment plays in shaping the essentialist content of racial beliefs. If all social categories are essentialized (or essentialized to the same degree), then it does not make much sense to pose the question as we have.

Ken Springer $(1992,1995)$ reports a series of studies that help determine the extent to which racial cognitions are peculiar in this regard. Using fundamentally the same switched-at-birth task, he found that preschool children believe that children will physically resemble their birth parents. Moreover, they attribute this resemblance to a material yet nonobvious substance that passes from the mother to the fetus during 
pregnancy. Importantly, Springer showed that children do not essentialize all possible parent/child resemblances. His switched-at-birth study asked children about a range of possible resemblances, including ones involving physical properties (such as being tall versus short), nonphysical properties (such as beliefs), and preferences (such as likes dogs more than cats). He found that children were nativists only about biologically relevant physical properties (i.e., being tall versus short), not nonphysical properties or preferences. These findings considerably narrow the field: young children seem to be nativists about biologically based physical properties.

But pace my initial claim, given that children are nativists about several biological properties, Springer's data do not seem to support the idea that race is more deeply essentialized than other properties. My claim is that in virtue of the human kind-making module, racial concepts (i.e., race as a category of mind) have a singular structure, and that by extension they play a special, singular role in reasoning. If young children believe that all physical properties are equally natural, the value of these data to the racial chicken-and-egg question is much diluted. The relevant developmental question accordingly is whether race is more deeply and more precociously essentialized than other physical properties. To see whether this is the case, we asked another group of preschool children about another set of couples and their switched-at-birth offspring. In this second study the parents contrasted not only in their race but in their physique. There were two conditions: half the children were told about a black and hefty couple and a white and wiry couple; the other half were told about a black and wiry couple and a white and hefty couple. The same switched-at-birth story was used. In this case, however, children were faced with the choice of offspring that matched parents in either race or in physique (thus, for children in the first condition the choices were a black, wiry child or a hefty, white one). The results were both informative and unambiguous. Even quite young children overwhelmingly reasoned that children would share racial but not physical properties with their birth parents. Bear in mind that the contrast was not fat and thin but hefty and wiry, aspects of physique that are as inherited and relevant to group identity as skin color (Bodmer and Cavalli-Sforza 1976; Cavalli-Sforza and Cavalli-Sforza 1995). ${ }^{7}$

What accounts for this readiness of younger children to naturalize race more than physique? Is it a function of children finding race to be inherently more relevant to group identity than physique? I do not believe that evidence supports this. By distinguishing children's culture, thought, and experience from adults, I am not suggesting that children and adults live in separate worlds. Clearly they share much of their life space. Recall that earlier I argued that the human kind module underdetermines racial 
belief. The module guides the development of belief by channeling attention toward some hypotheses and away from others. It triggers a curiosity about ontology but does not specify the specific elements of the ontology. Part of the reason that children place more "natural" weight on race than on physique is that in American society race is both named and highly salient cultural categories while physique is not. Adults provide the human kind categories, children provide the means of interpreting them. In short, I do not believe that children naturally naturalize race; rather, they naturally naturalize those social dimensions that the ambient cultural tradition marks as salient. In this sense culture and cognition, as Shweder (1990) has argued, make each other up.

\section{EONELUSION}

Together these studies lend support to the claim that children, even quite young children, essentialize and naturalize race. They also appear to do so in large measure on their own. While children and adults share a narrative about race, they share only part of that narrative. For children, an essentialized construal of race emerges and is elaborated long before it is understood that race is a factor in an ideological and political system of power. It makes little sense, accordingly, to say that this juvenile construal is a function of the political economic environment.

Indeed, these findings suggest another interpretation of the relationship between race as a category of power and as a category of mind. Race, as Hall (1980) remarked in the passage cited earlier, "naturally" naturalizes. Race has in itself-in its psychological core-a naturalizing and essentializing potency that makes it a particularly powerful political trope. Instead of seeing this potency as derived from the political economic environment, as comparativists have typically done, it makes more sense to argue that the political environment recruits a particular way of viewing and reasoning about human difference, because this particular way of viewing the world has important consequences for how readily a system of power and domination can be implemented. Race is a category of power because it is a peculiar category of the mind.

Again, it is important here to stress what I am not proposing. In arguing that young children are nativists about race I am not suggesting that they have an innate notion of race. Instead, what I suggest is that children spontaneously explore the social world around them in search of intrinsic human kinds or groups of individuals that are thought to bear some deep and enduring commonality. Different cultures inscribe the social environment with different human kinds. While race is one of the most recurring of these, it is not the only one. Gender, caste, age grade, and class are all examples of intrinsic human kinds. Race itself-the idea 
of race-is not innate. Rather it is the product of this spontaneous curiosity about human kinds as it engages a particular cultural formation.

Nor do I suggest that children discover race independent of the cultural environment in which they live: not all cultural formations are racialized, so not all children will spontaneously discover race. Children in, say, North America discover race precisely because race is entrenched in the North American cultural environment, and racial ideas, discourse, and practice saturate it. Arguing this, however, is not the same as arguing that children discover race simply because they encounter the political economic relations of race. In view of their limited understanding of political economy and the absence of race from the power relations they do engage, it would be a difficult task for young children to do this (see Hirschfeld 1996 for a more detailed discussion of this point). Young children discover race because their spontaneous, endogenous curiosity makes contact with the categories of their parents' minds. They do this because race is easy to think-easier perhaps than other dimensions of power, like class, that are often more fundamental to the distribution of power and authority. In turn, systems of power continue to make contact with and recruit race because it is easy to think. In so doing, our cognitive architecture makes a political architecture possible.

The evidence I review here accords well with this claim but does not rule out other possibilities. One way to strengthen the claim would be to replicate the effect in other contexts. For example, in South Asia the most relevant human kinds are arguably caste and, by extension, occupation. If I am correct in my argument, South Asian children should essentialize and naturalize caste and even occupation, but not (or to a much lesser degree) race. Similarly there are many systems of racial belief in which marked differences in appearance play little or no role. There is no reason to believe that essentialization and naturalization are linked to actual differences in appearance. How would children in these traditions perform on the tasks I have described here? What kinds of tasks would be needed to assess belief in such contexts? Much work needs to be done, and happily it is work that combines rather than opposes the insights of anthropologists, historians, and psychologists.

\section{MIISS}

Acknoweledgments. Versions of this paper were read at a panel on "Culture, psychology, and the construction of race" at the Biennial Meetings of the Society for Psychological Anthropology, San Juan, October 1995, and at a conference on "Race, power, and the mind" at the University of Michigan, Ann Arbor, February 1996. I thank Doug Medin, Dick Nishett, Ann Stoler, and two anonymous reviewers for their helpful comments. I gratefully acknowledge support from the NSF (SBR-9319796, INT-8814397, RCD-8751136) that made the research reported here possible. 


\section{8 - ETHOS}

1. Equally important to point out is that race is not the biological cause of any of these outcomes, despite the popularity that such claims enjoy. Race cannot be a biological cause because race is not a biologically coherent notion. There is as much genetic variation within races as there is between them. As such race can hardly carry a biological effect (any more than being a lawyer can carry-i.e., cause-a biological effect, in spite of the fact that being a lawyer might be correlated with some biological outcomes).

2. Where the essentializing heuristic comes from is still a matter of considerable controversy. As noted, Medin (1989) sees it as a domain-general phenomenon. Carey (1995) too suggests a domain-general origin but links essentializing to language, specifically the fact that language forces us to put sets of similar things into categories. Others, particularly Atran (1990), argue that essentialist reasoning is initially part of a living-kind module (sometimes called a folk biological module) and only later is it extended via analogy to other domains. I have presented evidence that the developmental data do not support this claim (Hirschfeld 1995). Keil (1994) provides a key to an alternative account of essentialism's origins. He proposes a model of cognitive architecture in which a set of innate modes of construal come to be associated with a specific domain of the world but are not intrinsically associated with these domains. The essentializing heuristic might be one of these "free-floating" modes of construal. The issue, however, is not resolved.

3. I say "later developing" because there is little reason to believe that prior to the age of overseas exploration, people encountered individuals whose morphology was marked by differences that we now think of as racial (van den Berghe 1981).

4. Ariès is also associated with the claim that prior to the 17 th century people did not distinguish childhood from adulthood. Clearly images of childhood vary considerably across cultures, but there is no compelling evidence to doubt that all cultures recognize a period of immaturity and spectacular growth in competence.

5. Three- and five-year-olds were tested because other studies have shown that the preschool years are the period in which essentializing in other domains emerges and the period in which notions of kindhood are much elaborated. It thus makes sense to explore whether racial essentializing emerges and whether human kinds are particularly elaborated during this time.

6. Children were drawn from preschools in the Ann Arbor area. Ann Arbor is an overwhelmingly white and middle-class community, and there was no indication that the racial distribution of children who participated in the study differed from that of the community at large. In any event, no attempt was made to include or exclude children by race or ethnicity. Indeed, no attempt was made to record the children's race or ethnicity.

7. For decades physical anthropologists collected detailed skull measurements in an effort to develop coherent categories based on anthropometics. These classifications often failed to correspond with subsequent classifications based on internal properties like the genes that determine blood groups, leading many to conclude that racial classifications (which seek to capture in a single system of classification both internal and external attributes) lack a scientific basis (Brace 1964; Molnar 1992). Nonetheless, it is apparent that variations in body type, size, and proportion are inherited qualities, being complex adaptations to environmental conditions. As Cavalli-Sforza and Cavalli-Sforza note, "external body features, such as skin color, and body size and shape, are highly subject to the influence of natural selection due to [genetic adaptation to variations in] climate" (1995:115). That inherited patterns of variation in body type are of less social importance to most of us living in North America than inherited patterns of variation in skin color reveals little about how much such information beckons the attention of a observer. If the "playing field" is flat-if all patterned variation in external appearance are equally demanding of attention-then there is no reason why children should reason more deeply ahout differences in skin color than body-build. 


\section{RIPBDERS EIIE}

Aboud, Francis E.

1988 Children and Prejudice. New York: Basil Blackwell.

Adorno, Theodor W., E. Frenkel-Breusnwik, D. Levinson, and R. N. Sanford

1950 The Authoritarian Personality. New York: Harper and Row.

Alba, Richard

1985 Italian Americans: Into the Twilight of Ethnicity. Englewood Cliffs, NJ: Prentice-IIall.

Alexander, Richard

1979 Darwinism and Human Affairs. Seattle: University of Washington Press.

1987 The Biology of Moral Systems. Hawthorne, NY: Aldine.

1989 Evolution of the Human Psyche. In The Human Revolution: Behavioural and

Biological Perspective on the Origins of Modern Humans. Paul Mellars and Chris Stringer,

eds. Pp. 455-513. Princeton, NJ: Princeton University Press.

Alport, Gordon

1954 The Nature of Prejudice. Cambridge, MA: Addison-Wesley.

Amit-Talai, Vered, and Helena Wulff

1995 Youth Cultures: A Cross-Cultural Perspective. New York: Routledge.

Appiah, Kwame A.

1990 Race. In Critical Terms for Literary Study. Frank Lentriccha and Thomas McLaughin, eds. Pp. 274-287. Chicago: University of Chicago Press.

Ariès, Philippe

1962 Centuries of Childhood: A Social History of Family Life. New York: Vintage.

Atran, Scott

1990 Cognitive Foundations of Natural History. New York: Cambridge University Press.

Bloch, Maurice

1974 Symbols, Song, Dance and Features of Articulation: Is Religion an Extreme for

Traditional Authority? European Journal of Sociology 15:55-81.

Bodmer, Walter, and Luigi Cavalli-Sforza

1976 Genetics, Evolution, and Man. San Francisco, CA: W. H. Freeman and Co.

Brace, C. Loring

1964 A Non-Racial Approach toward the Understanding of Human Diversity. In The

Concept of Race. Ashley Montagu, ed. Pp. 102-151. Lincoln: University of Nebraska Press.

Brereton, A.

1996 Coercion-Defense Hypothesis: The Evolution of Primate Sociality. Folia Primatol 64:207-214.

Carey, Susan

1985 Conceptual Development in Childhood. Cambridge: Massachusetts Institute of Technology Press.

1995 On the Origin of Causal Understanding. In Causal Cognition. Dan Sperber, David Premack, and Ann Premack, eds. New York: Oxford University Press.

Carey, Susan, and Elizabeth Spelke

1994 Domain Specific Knowledge and Conceptual Change. In Mapping the Mind: Domain Specificity in Cognition and Culture. Lawrence Hirschfeld and Susan Gelman, eds. Pp. 169-200. New York: Cambridge University Press.

Cavalli-Sforza, Luigi, and Francesco Cavalli-Sforza

1995 The Great Human Diasporas: The History of Diversity and Evolution. Reading, MA: Addison-Wesley Publishing.

Cheney, Dorothy, and Robert Seyfarth

1990 How Monkeys See the World: Inside the Mind of Another Species. Chicago: University of Chicago Press. 
Corsaro, William, and Donna Eder

1990 Children's Peer Cultures. Annual Review of Sociology 16:197-220.

Dominguez, Virginia

1986 White by Definition: Social Classification in Creole Louisiana. New Brunswick, NJ:

Rutgers University Press.

Doyle, Anna Beth

1983 Friends, Acquaintances, and Strangers: The Influence of Familiarity and Ethnolin-

guistic Background on Social Interaction. In Peer Relationships and Social Skills in

Childhood. Kenneth Rubin and Holly Ross, eds. London: Springer-Verlag.

Dunbar, Robin

1988 Primate Social Systems. Ithaca, NY: Cornell University Press.

Emmerich, Walter, Karla Goldman, Barbara Kirsch, and Ruth Sharabany

1977 Evidence for a Transitional Phase in the Development of Gender Constancy. Child

Development 48:930-936.

Fanon, Frantz

1968 Black Skin, White Masks. London: MacGibbon and Kee.

Fields, Barbara

1982 Ideology and Race in American History. In Region, Race and Reconstruction. J.

Morgan Kausser and James McPherson, eds. Pp. 143-177. New York: Oxford University Press.

Fishbein, Harold

1996 Peer Prejudice and Discrimination: Evolutionary, Cultural, and Developmental

Dynamics. Boulder, CO: Westview Press.

Fiske, Susan, and Shelley Taylor

1991 Social Cognition. New York: McGraw Hill.

Fried, Morton

1975 The Notion of the Tribe. Menlo Park, CA: Cummings.

Fuss, Diana

1989 Essentially Speaking: Feminism, Nature and Difference. New York: Routledge.

Gelman, Susan, Pamela Collman, and Eleanor Maccoby.

1986 Inferring Properties from Categories versus Inferring Categories from Properties:

The Case of Gender. Child Development 57:396-404.

Gelman, Susan, John Coley, and Gail Gottfried

1994 Essentialist Beliefs in Children: The Acquisition of Concepts and Theories. In

Mapping the Mind: Domain Specificity in Cognition and Culture. Lawrence Hirschfeld and Susan Gelman, eds. Pp. 341-365. New York: Cambridge University Press.

Goldberg, David

1993 Racist Culture: Philosophy and the Politics of Meaning. New York: Basil Blackwell.

Guillaumin, Colette

1980 The Idea of Race and Its Elevation to Autonomous Scientific and Legal Status.

Sociological Theories: Race and Colonialism, Paris, 1980. UNESCO.

Hall, Stuart

1980 Race, Articulation and Societies Structured in Dominance. In Sociological Theories:

Race and Colonialism. Pp. 305-346. Paris: UNESCO.

Ilamilton, David L., and Robert K. Gifford

1976 Illusory Correlation in Interpersonal Perception: A Cognitive Basis of Stereotypic Judgement. Journal of Experimental Social Psychology 12:392-407.

Hirschfeld, Lawrence

1988 On Acquiring Social Categories: Cognitive Development and Anthropological Wisdom. Man 23:611-638.

1993 Discovering Social Difference: The Role of Appearance in the Development of Racial $\Lambda$ wareness. Cognitive Psychology 25:317-350. 
1995 Do Children Have a Theory of Race? Cognition 54:209-252.

1996 Race in the Making: Cognition, Culture, and the Child's Construction of Human

Kinds. Cambridge: Massachusetts Institute of Technology Press.

Hirschfeld, Lawrence, Scott Atran, and Aram Yengoyan

1982 Theories of Knowledge and Culture. Social Science Information 21:161-198.

Hirschfeld, Lawrence, and Susan Gelman

1994 Mapping the Mind: Domain Specificity in Cognition and Culture. New York: Cambridge University Press.

Holmes, Robin

1995 How Young Children Perceive Race. Thousand Oaks, CA: Sage Publications.

Jackson, James, Wayne McCullough, and Gerald Gurin

1988 Family, Socialization Environment, and Identity Development in Black Americans.

In Black Families. H. P. McAdoo, ed. Pp. 242-256. Newbury Park, CA: Sage Publications.

Katz, Phyllis

1982 Development of Children's Racial Awareness and Intergroup Attitudes. In Current

Topics in Early Childhood Education, vol. 4. L. Katz, ed. Pp. 16-54. Norwood, NJ: Ablex.

Keil, Frank

1994 The Birth and Nurturance of Concepts by Domains: The Origins of Concepts of

Living Things. In Mapping the Mind: Domain Specificity in Cognition and Culture.

Lawrence Hirschfeld and Susan Gelman, eds. Pp. 234-254. New York: Cambridge

University Press.

Kofkin, J., Phyllis Katz, and E. Downey

1995 Family Discourse about Race and the Development of Children's Racial Attitudes.

Bienniel Meetings of the Society for Research in Child Development, Indianapolis,

Indiana, 1995.

Kohlberg, Lawrence

1966a Cognitive-Developmental Analysis of Children's Sex-Role Concepts and Attitudes.

In The Development of Sex Differences. E. Maccoby, ed. Pp. 82-173. Palo Alto, CA:

Stanford University Press.

Lévi-Strauss, Claude

1969 The Elementary Structures of Kinship. Boston, MA: Beacon Press.

Mannoni, Octave

1964 Prospero and Caliban: The Psychology of Colonialism. New York: Praeger.

Marks, Jonathon

1995 Human Biodeversity: Genes, Race, and History. New York: Aldine de Gruter.

Massey, Douglas

1993 American Apartheid: Segregation and the Making of the Underclass. Cambridge, MA:

Harvard University Press.

Medin, Douglas

1989 Concepts and Conceptual Structure. American Psychologist 44:1469-1481.

Mehler, Jacques, Peter Juscyzk, Ghislaine Lambertz, Nilofar Halsted, Josiane Bertoncini, and Claudine Amiel-Tison

1988 A Precursor of Language Acquisition in Young Infants. Cognition 29:143-178.

Molnar, Stephen

1992 Human Variation: Races, Types, and Ethnic Groups. Englewood Cliffs, NJ: Prentice

Hall.

Putnam, Hilary

1975 The Meaning of "Meaning." In Mind, Language and Reality: Philosophical Papers,

vol. 2. H. Putnam, ed. Pp. 215-271. New York: Cambridge University Press.

Quattrone, George, and Edward Jones

1980 The Perception of Variability within Ingroups and Outgroups: Implications for the

Law of Small Numbers. Journal of Personality and Social Psychology 38:141-152. 


\section{Ramsey, Patricia}

1987 Young Children's Thinking about Ethnic Differences. In Children's Ethnic Socialization: Pluralism and Development. Jean Phinney and Mary Jane Rotheram, eds. Pp. 56-72. Newbury Park, CA: Sage.

Reynolds, Vernon, Vincent Galger, and Ian Vine

1987 The Sociobiology of Ethnocentrism: Evolutionary Dimensions of Xenophobia, Dis-

crimination, Racism, and Nationalism. London: Croom Helm.

Roediger, David

1994 Towards the Abolition of Whiteness: Essays on Race, Politics, and Working Class History. New York: Verso.

Rosenberg, Morris

1979 Conceiving the Self. New York: Basic Books.

Semaj, Leancim

1980 The Development of Racial Evaluation and Preference: A Cognitive Approach. The Journal of Black Psychology 6:59-79.

Shaw, R. Paul, and Yuma Wong

1989 Genetics Seeds of Warfare: Evolution, Nationalism, and Patriotism. Boston, MA: Unwin Hyman.

Shweder, Richard

1990 Cultural Psychology - What Is It? In Cultural Psychology: Essays on Comparative

Human Development. R. S. J. Stigler and G. Herdt, eds. Pp. 1-43. New York: Cambridge University Press.

Slaby, Ronald, and Karin Frey

1975 Development of Gender Constancy and Selective Attention to Same-Sex Models.

Child Development 46:849-856.

Smedley, Audrey

1993 Race in North America: Origin and Evolution of a Worldview. Boulder, CO: Westview

Press.

Sollors, Werner

1986 Beyond Ethnicity: Consent and Descent in American Culture. New York: Oxford University Press.

\section{Springer, Ken}

1992 Children's Awareness of the Biological Implications of Kinship. Child Development

63:950-959.

1995 The Role of Factual Knowledge in a Naive Theory of Biology. Biennial Meetings of

the Society for Research in Child Development, Indianapolis. Indiana, 1995.

Tajfel, Ilenri

1981 Human Groups and Social Categories. Cambridge: Cambridge University Press.

Takaki, Ronald

1992 The Tempest in the Wilderness: The Racialization of Slavery. The Journal of American History 79:892-912.

Van den Berghe, Pierre L.

1981 The Ethnic Phenomenon. New York: Elsevier.

Warnecke, Michael $\Lambda$., Roger Masters, and Guido Kempter

1992 The Roots of Nationalism: Nonverbal Behavior and Xenophobia. Ethology and Sociobiology 13:267-282.

Winant, Howard

1994 Racial Conditions: Politics, Theory, Comparisons. Minneapolis: University of Minnesota Press.

Wrangham, Richard

1980 An Ecological Model of Female-Bonded Primate Group. Behaviour 75:262-300. 